\title{
Prevalence of pre-diabetes and risk factors among secondary school adolescents in Osogbo Local Government Area, Osun State, Nigeria
}

\author{
Nafisat O Akintayo-Usman ${ }^{1}$, Funmilayo A Okanlawon², Saheed O Usman ${ }^{3}$
}

1. Nurse Tutors' Programme, University College Hospital, Ibadan, Nigeria.

2. Department of Nursing, College of Medicine, University of Ibadan, Nigeria.

3. Department of Chemical Pathology, Nnamdi Azikiwe University Awka, Nigeria.

\section{E-mails:}

Nafisat O Akintayo-Usman: naffydee@yahoo.co.uk, +2348069812292; Funmilayo A Okanlawon: funmilayookanlawon@yahoo.com,+2348055071838; Saheed O Usman: senatorhopsy@yahoo.com, $+2348034676223$

\begin{abstract}
Background: Pre-diabetes is an emerging public health challenge in sub-Saharan Africa.

Objectives: To estimate prevalence of pre-diabetes and assess its associated factors among adolescents. The risk factors were divided into individual, interpersonal and community factors, adapting socio-ecological model.

Methods: This study utilised a cross-sectional descriptive survey. The target population was secondary school adolescents of Osogbo Local Government. Questionnaire was used to interview 405 participants through multi-stage sampling. Prediabetes was measure through fasting blood glucose.

Results: Findings revealed prevalence rate of $9.4 \%$. Individual factors identified to be significant include age, religion and family history. Further analysis showed adolescents with normal BMI and high BP are likely to develop pre-diabetes when compared to those with underweight and normal BP respectively. Among interpersonal factors, parents' dietary habit was significant. Also, adolescents with employed parents were likely to develop pre-diabetes compared to those with unemployed parents. Lastly, availability of healthy food in school was the only statistically significant community factor. Hence, the more availability of food, fruits and vegetables in schools, the less likelihood of developing prediabetes.

Conclusion: These findings affirmed that prediabetes is becoming common problem among Nigerian adolescents. There is therefore need for stakeholders to face this challenge before it becomes endemic.

Keywords: Pre-diabetes; adolescents; individual factors; interpersonal factors; community factors.

DOI: https://dx.doi.org/10.4314/ahs.v21i3.41

Cite as: Akintayo-Usman NO, Okanlawon FA, Usman SO. Prevalence of pre-diabetes and riskefactors among secondary school adolescents in Osogbo Local Government Area, Osun State, Nigeria. Afri Health Sci. 2021;21(3). 1301-1309. https:/ / dx.doi.org/10.4314/ abs.v21i3.41
\end{abstract}

\section{Introduction}

More African people will die from non-communicable diseases (NCDs) than infectious diseases by 2030; with $27 \%$ increase in deaths expected over next ten years ${ }^{1,2}$. Meanwhile $75 \%$ of 415 million people living with diabetes are from low- and middle-income countries, with a prediction of reaching 642 million by $2040^{3}$. Prediabetes and Diabetes Mellitus (DM) are increasing problems in sub-Saharan Africa with type II DM being the most common ${ }^{4}$.

\section{Corresponding author: \\ Nafisat O Akintayo-Usman, \\ Nurse Tutors' Programme, \\ University College Hospital, Ibadan, Nigeria. \\ Email: naffydee@yahoo.co.uk}

Prediabetes is defined as plasma glucose levels that are elevated above the normal range, but below the threshold for diabetes. World Health Organisation (WHO) defines prediabetes as Fasting Plasma Glucose, FPG level of $110-125 \mathrm{mg} / \mathrm{dL}$ and/or Oral Glucose Tolerance Test, OGTT of $140-200 \mathrm{mg} / \mathrm{dl}$; while International Society for Pediatric Adolescent Diabetes (ISPAD) defines it as FPG of $100-125 \mathrm{mg} / \mathrm{dl}$ or OGTT of $140-200 \mathrm{mg} / \mathrm{dl}^{5,6}$. It does not have to result in diabetes if identified early, as lifestyle changes are enough to prevent it from progressing to diabetes. It is therefore important for adolescents to know their pre-diabetic status, because research has shown that some long-term complications associated with diabetes - such as heart disease - may begin during pre-diabetes ${ }^{7}$. 
Globally, an increase in epidemiological trends of prediabetes' prevalence among adolescents has been reported - as in the general population - regardless of the race $^{8}$. The prevalence of Impaired Glucose Tolerance, across age groups, is reported to be $9.7 \%$ in Africa; 4.5\% in Europe; $7.6 \%$ in Middle East and North Africa; $10.7 \%$ in North American and Caribbean; 5.4\% South and Central American; 3.0\% in South East Asia; and $5.4 \%$ in Western Pacific ${ }^{9}$. New York State Department of Health noted that among the risk factors for type II DM in children is being African American, Hispanic or Latino American, American Indian, Asian American, or Pacific Islander ${ }^{10}$. However, a review reported highest prevalence among Native Americans and Non-Hispanic Black with prevalence rates of 1.45 and 1.06 per 1000 adolescents respectively; Asian and Pacific Island adolescents have similar prevalence rates of 0.52 and 0.46 per 1000; while the Non-Hispanic White has the lowest prevalence rates 0.18 per $1000^{9}$.

Though the prevalence of prediabetes among children is reaching alarming rates across the globe, the actual global prevalence remains unknown ${ }^{11,12}$. A prevalence of DM and prediabetes was reported to $10.83 \%$ among children and adolescents in Saudi Arabia ${ }^{13}$. In a study among adolescents in Eastern Iran, the FBS in many of the total population (59.6\%) was in the upper limit of normal range ${ }^{14}$. In Hungary, $13 \%$ of overweight adolescents was at high risk of developing type II $\mathrm{DM}^{15}$. The prevalence of prediabetes was 5.4\% among Emirati overweight/obese children and adolescents ${ }^{11}$. Also, in the District of Abidjan in Cote d'Ivoire, the prevalence of IFG was $14.5 \%$ among children and adolescents ${ }^{16}$.

Despite prediabetes being an emerging public health challenge in sub-Saharan Africa, Nigeria inclusive, there is little research focus on adolescents ${ }^{17}$. Only a few studies have been conducted on its prevalence among $\mathrm{Ni}$ gerian adolescents. A prevalence of $17 \%$ was reported in Port-Harcourt, while $4.0 \%$ was reported in Ibadan - using ISPAD criteria ${ }^{17,18}$. The need for a similar study to contribute to literature on the prevalence prompted this study.

Social Ecological Model, the theoretical framework for the study, was into three-level to suit the study. The model was used to consider the complex interplay between individual, relationship and community factors. An individual's various traits and identities make up the first level - interpersonal factors. It identifies biological and personal history factors that increase the likelihood of becoming pre-diabetic. Some of these factors are age, gender, financial resources, socio-economic status, race/ethnicity, religious identity, physical health, knowledge, attitudes, behaviour, self-concept, skills, developmental history, genetis, health literacy and personal preferences are some of the many attributes noted at this interval ${ }^{19-21}$. The second level of SEM is the interpersonal factors. A person's closest social circle - peers, partners and family members - influences their behaviour ${ }^{19}$. The third level is the community factors. SEM explores the settings, such as schools, workplaces, and neighbourhoods, in which social relationships occur $^{19}$. Hence, the aim of the study was to estimate the prevalence of pre-diabetes, while the specific ones were to the individual, interpersonal and community factors associated with the prevalence of prediabetes among these adolescents.

\section{Methods}

This study utilised a cross-sectional descriptive survey to conduct the study in Osogbo Local Government Area (LGA) - the major LGA in Osogbo metropolis. The target population for this study was secondary school adolescents of the LGA, while study population was the adolescents of the four selected schools. The minimum sample size calculated for this study was 310 participants, using Cochran formula - with adjustment of $20 \%$ for non-response and $10 \%$ for those the researchers were unable to contact ${ }^{22}$. The estimated sample size was distributed proportionately between public $(91.7 \%)$ and private $(8.3 \%)$ schools using enrolment rate $^{23}$. Hence, the minimum sample size for public and private was 285 and 26 respectively. However, Sudman recommended in 1976 that a minimum of 100 participants be recruited in each major group to accommodate a comparative analysis ${ }^{22}$. Hence, the minimum sample size for the study was 385 participants, with sample size of 100 for private school. Eventually, 410 adolescents were recruited using multi-stage sampling technique. However, five was eventually excluded (one for being absent and four for failing to fast during the week of data collection). Hence, 405 adolescents participated in the study.

Inclusion criteria were secondary school adolescents between the ages of 10 and 19 years $^{24}$, who had not been diagnosed with DM and whose parents gave informed consent. Exclusion criteria were adolescents who on the day of study, were absent, ate before coming and/or sick. An interviewer-administered questionnaire, which had eight sections with forty main items, 
was used. Five sections were developed by the researchers, while three sections were adapted from questionnaire on knowledge of women on gestational diabetes, Godin Leisure-Time Exercise Questionnaire and Adolescent Food Habits Checklist respectively ${ }^{25-27}$.

Approval letter and ethical approval certificate were obtained from Osun State Ministries of Education and Health respectively, after which permission was sought from respective school principals. An information sheet/consent form was sent to parents of all adolescents attending the selected schools. Only adolescents whose parents signed the consent form were included in the study. Parents were asked to ensure their children did not take breakfast on the day of the study until they have been tested. For the adolescents, purpose and procedure of the study, as well as the importance of not eating until the test is done were explained to thm on the day prior data collection. After this, adolescents who met the inclusion criteria and gave verbal assent were interviewed. Confidentiality of all data gathered was maintained. To avoid contamination, universal safety precautions were strictly adhered to when carrying out the finger prick test. For ethical reasons, awareness on prediabetes was created among parents, teachers and students. Results of the tests were communicated to the adolescents and their parents by sending Short Message Service (SMS) to their respective parents; and all students with abnormal glucose and Blood pressure (BP) levels were referred to their family physician.

Participants' B/P was first checked, to avoid being stressed, with the aid of Accosson mercury sphygmomanometer - while sitting and well comfortable on chair. After this, the FBG was measured by finger prick test with the aid of Accu-chek active glucometer while still on sit. Weight and height were then be measured while standing on the Generic Height and Weight with no shoes. Body Mass Index (BMI) was categorized according to BMI percentile charts for age and sex by WHO using BMI-for-Age growth charts into underweight $\left(<5^{\text {th }}\right.$ percentile), normal weight $\left(5^{\text {th }}\right.$ to $<85^{\text {th }}$ percentile), overweight $\left(85^{\text {th }}\right.$ to $<95^{\text {th }}$ percentile) and obesity ( $\geq 95^{\text {th }}$ percentile). BP was classified with the aid of 2017 American Academy of Pediatrics Guidelines for Childhood Hypertension. The BP percentiles based on age, gender and height was then determined and classified ${ }^{28}$. Meanwhile, FBG result was classified based on the ISPAD criteria. Data were coded and entered into computer with the aid of Statistical Packages for Social Sciences - version 24. Descriptive statistics was used to analyse the main objective. Binomial logistic regression test was used to analyse all the hypotheses, where values of $\mathrm{p}<0.05$ were considered statistically significant and $\mathrm{P}<0.01$ were considered highly statistically significant.

\section{Results}

The mean age of the participants was $15.40+2.51$; from this, those whose age was 10-15 years were regarded as 'middle adolescents' while those 16-19 years were 'late adolescents'. Hence, 50.6\% $(n=205)$ were middle adolescents, while $49.4 \%(n=200)$ were late adolescents. Also, $74.6 \%(\mathrm{n}=302)$ were females, while $25.4 \%$ $(n=103)$ were males; $44.9 \%(n=182)$ were Christians and $55.1 \%(n=223)$ were Muslims; $74.3 \%(n=301)$ were from public schools while $25.7 \%(n=104)$ were from private schools.

The mean weight of participants was $46.3+10.4 \mathrm{~kg}$, median height $1.57 \mathrm{~m}$, mean BMI $18.7+3.1 \mathrm{~kg} / \mathrm{m}^{2}$, mean FBG $88.4+9.2 \mathrm{mg} / \mathrm{dl}$, mean Systolic BP 102.5 $+12.3 \mathrm{mmHg}$ while the mean Diastolic BP was $66.6+$ $11.5 \mathrm{mmHg}$. Furthermore, it was deduced that $20.2 \%$ $(n=82)$ of participants were underweight, $73.8 \%$ $(\mathrm{n}=299)$ had normal BMI, 3.5\% $(\mathrm{n}=14)$ overweight while $2.5 \%(n=10)$ were obese; $88.4 \%(n=358)$ had normal BP, 7.9\% ( $n=32)$ had elevated BP, 3.0\% $(n=12)$ had stage I hypertension while $0.7 \%(n=3)$ had stage II hypertension. From figure I, 90.6\% $(n=367)$ had normal FGB level, 9.4\% $(\mathrm{n}=38)$ had pre-diabetes and none was diabetic. Hence, the prevalence rate was $9.4 \%$. Out of the 38 prediabetic participants, 3 were hypertensive, 5 had elevated $\mathrm{BP}$ and 30 had normal BP; while for BMI, 3 was underweight, and 35 had normal BMI (see table I). It is worthy of note that there is positive correlation between the BP and BMI of the participants. 


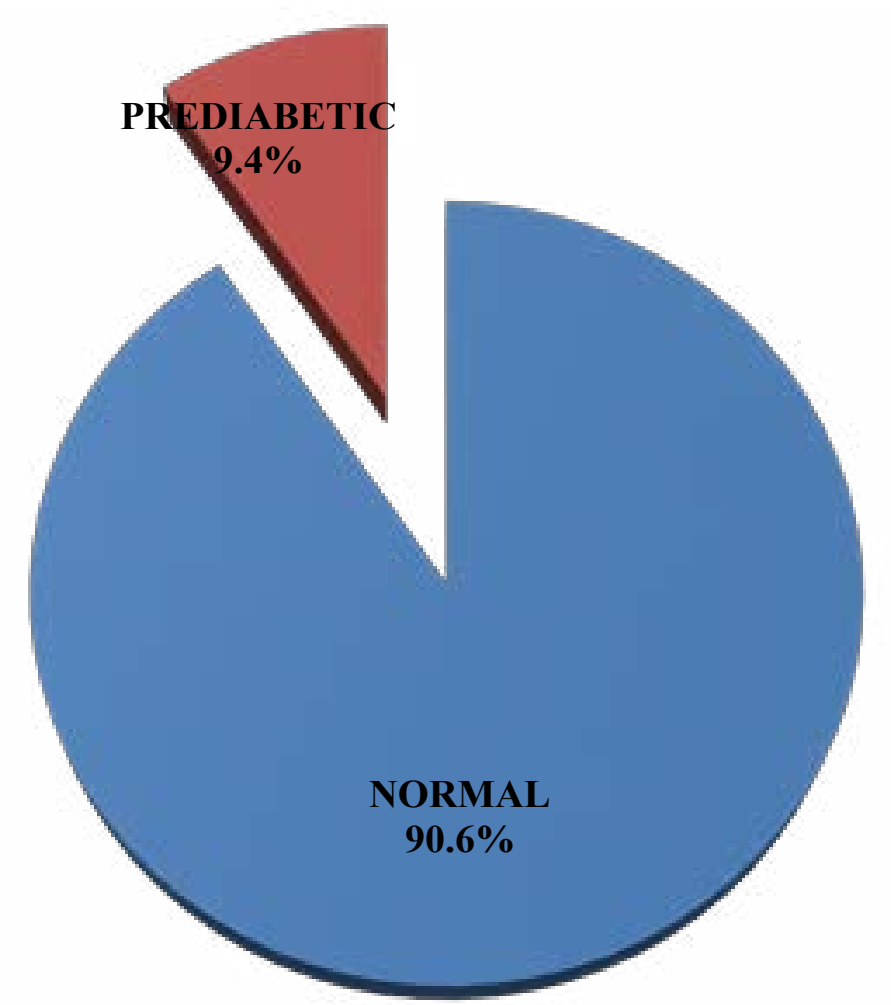

Figure I: Distribution of pre-diabetes among secondary school adolescents in Osogbo Local Government Area

Table I: Crosstabulation of FBG, BP and BMI of participants

\begin{tabular}{|lll|l|l|l|}
\hline \multirow{2}{*}{ BP Category } & & & FBG Category & \\
\cline { 3 - 6 } & & & Normal & Prediabetic & Total \\
\hline Hypertension & BMI & Overweight/Obese & 1 & 0 & 1 \\
& category & Normal & 8 & 3 & 11 \\
& & Underweight & 3 & 0 & 3 \\
\hline & Total & & 12 & 3 & 15 \\
\hline Elevated BP & BMI & Overweight/Obese & 5 & 0 & 5 \\
& category & Normal & 19 & 5 & 24 \\
& & Underweight & 3 & 0 & 3 \\
\hline Normal & Total & & 27 & 5 & 32 \\
& BMI & Overweight/Obese & 18 & 0 & 18 \\
& category & Normal & 237 & 27 & 264 \\
& & Underweight & 73 & 3 & 76 \\
\hline Total & Total & & 328 & 30 & 358 \\
& BMI & Overweight/Obese & 24 & 0 & 24 \\
& category & Normal & 264 & 35 & 299 \\
& & Underweight & 79 & 3 & 82 \\
\hline & Total & & 367 & 38 & 405 \\
\hline
\end{tabular}

For the first hypothesis, which predicts no statistically knowledge and genetics) and presence of pre-diabetes, significant relationship between the individual factors $90.6 \%$ of cases were correctly predicted by the model. (socio-demographic variables, lifestyle, physical health, Among the individual factors tested, only age, religion 
and family history were statistically significant (see table II). However, BMI was though insignificant, having normal BMI was statistically significant $(p=0.017)$ when compared to underweight adolescents. BP was also insignificant, but having hypertension was statistically significant when compared to those with normal BP.

Table II: Variables in the Equation for Hypothesis One

\begin{tabular}{|ll|l|l|l|l|l|l|}
\hline & B & S.E. & Wald & Df & Sig. & Exp(B) \\
\hline Step 1 & Age & -.232 & .081 & 8.203 & 1 & .004 & .793 \\
& Gender(1) & .195 & .474 & .169 & 1 & .681 & 1.215 \\
& Religion(1) & -1.487 & .498 & 8.895 & 1 & .003 & .226 \\
Type of school(1) & .498 & .474 & 1.100 & 1 & .294 & 1.645 \\
Physical activity & .010 & .008 & 1.665 & 1 & .197 & 1.010 \\
Dietary habit & .138 & .108 & 1.646 & 1 & .200 & 1.148 \\
BMI Category & & & 5.663 & 2 & .059 & \\
Overweight/Obese & -17.878 & 7491.558 & .000 & 1 & .998 & .000 \\
Normal BMI & 1.692 & .711 & 5.663 & 1 &. $\mathbf{0 1 7}$ & 5.432 \\
BP Category & & & 4.750 & 2 & .093 & \\
Hypertension & 1.626 & .797 & 4.161 & 1 &. $\mathbf{0 4 1}$ & 5.086 \\
Elevated BP & .694 & .664 & 1.092 & 1 & .296 & 2.002 \\
Knowledge & -.080 & .140 & .328 & 1 & .567 & .923 \\
Family history (1) & 1.463 & .605 & 5.840 & 1 & .016 & 4.318 \\
Constant & -1.572 & 1.483 & 1.124 & 1 & .289 & .208 \\
\hline
\end{tabular}

For the second hypothesis, which predicts no statistically significant relationship between the interpersonal factors (parent's socio-economic status, parent's lifestyle and friend's lifestyle) and presence of pre-diabetes, $91.4 \%$ of cases were correctly predicted by the model. Among the interpersonal factors tested, only par- ents' dietary habit was statistically significant (See table III). However, further analyses on parent's occupation showed higher risk of developing prediabetes is statistically significant in adolescents whose parents were traders/businessmen and public servants when compared those with unemployed parents.

Table III: Variables in the Equation for Hypothesis Two

\begin{tabular}{|c|c|c|c|c|c|c|c|}
\hline & & B & S.E. & Wald & Df & Sig. & $\operatorname{Exp}(B)$ \\
\hline \multicolumn{8}{|c|}{ Parent occupation } \\
\hline & Farmer/Artisan & -21.211 & 11495.452 & .000 & 1 & .999 & .000 \\
\hline & Trading/Business & -2.552 & .894 & 8.150 & 1 & .004 & .078 \\
\hline & Public servant & -2.152 & .925 & 5.415 & 1 & .020 & .116 \\
\hline & $\begin{array}{l}\text { Private sector } \\
\text { worker }\end{array}$ & -21.229 & 7381.539 & .000 & 1 & .998 & .000 \\
\hline & $\begin{array}{l}\text { Parent level of } \\
\text { education }\end{array}$ & & & 5.235 & 3 & .155 & \\
\hline & $\begin{array}{l}\text { No formal } \\
\text { education }\end{array}$ & 1.111 & .755 & 2.164 & 1 & .141 & 3.036 \\
\hline & $\begin{array}{l}\text { Primary } \\
\text { education }\end{array}$ & 1.212 & .773 & 2.463 & 1 & .117 & 3.361 \\
\hline & $\begin{array}{l}\text { Secondary } \\
\text { education }\end{array}$ & .806 & .432 & 3.482 & 1 & .062 & 2.238 \\
\hline & $\begin{array}{l}\text { Parent physical } \\
\text { activity }\end{array}$ & & & 2.559 & 2 & .278 & \\
\hline & No activity & -1.715 & 1.113 & 2.376 & 1 & .123 & .180 \\
\hline & Some activity & -.070 & .493 & .020 & 1 & .888 & .933 \\
\hline & $\begin{array}{l}\text { Parent dietary } \\
\text { habit }\end{array}$ & -.665 & .238 & 7.787 & 1 & .005 & .514 \\
\hline & $\begin{array}{l}\text { Friend physical } \\
\text { activity (1) }\end{array}$ & -.538 & .534 & 1.016 & 1 & .314 & .584 \\
\hline & $\begin{array}{l}\text { Friend dietary } \\
\text { habit (1) }\end{array}$ & .099 & .485 & .042 & 1 & .838 & 1.104 \\
\hline & Constant & 1.985 & 1.261 & 2.478 & 1 & .115 & 7.281 \\
\hline
\end{tabular}


For the third hypothesis, which predicts no statistically significant relationship between the community factors (home, school and neighbourhood) and presence of pre-diabetes, $90.6 \%$ of cases were correctly predicted by the model. Among the community factors tested, only availability of healthy food in school was statistically significant (see table IV). Further analysis showed that availability of food, fruits and vegetables in school were highly statistically significant when compared with availability of soft drink, snacks and biscuits in school.

Table IV: Variables in the Equation for Hypothesis Three

\begin{tabular}{|l|r|r|r|r|r|r|}
\hline & \multicolumn{1}{|c|}{ B } & \multicolumn{1}{c|}{ S.E. } & \multicolumn{1}{c|}{ Wald } & df & Sig. & Exp(B) \\
\hline Step 1 Home healthy food & -.654 & .396 & 2.732 & 1 & .098 & .520 \\
availability (1) & .278 & .528 & .276 & 1 & .599 & 1.320 \\
School's sport facilities (1) & -18.784 & 6718.237 & .000 & 1 & .998 & .000 \\
School's safety (1) & & & 15.599 & 2 &. $\mathbf{0 0 0}$ & \\
School's healthy food & & & & & \\
availability & 1.464 & .438 & 11.178 & 1 &. $\mathbf{0 0 1}$ & 4.322 \\
$\quad$ Food & 1.890 & .662 & 8.145 & 1 &. $\mathbf{0 0 4}$ & 6.619 \\
$\quad$ Fruits and Vegetables & & & 3.455 & 2 & .178 & \\
Neighborhood healthy & & & .000 & 1 & .997 & .000 \\
foods availability & -19.462 & 5966.312 & .998 & .294 \\
$\quad$ Food & -1.224 & .658 & 3.455 & 1 & .063 & .325 \\
$\quad$ Fruits and Vegetables & -1.193 & 1.047 & 1.298 & 1 & .255 & .303 \\
Neighborhood safety (1) & -1.948 & .317 & 37.683 & 1 & .000 & .143 \\
Constant
\end{tabular}

\section{Discussion}

Considering the age distribution of participants with elevated parameters, more overweight participants were middle adolescents, while majority of the obese were late adolescents. This means that as they grow older, overweight adolescents are likely to become obese unless they modify their lifestyle ${ }^{29}$. This trend is similar for the development of hypertension, as there are more middle adolescents with elevated blood pressure and stage I hypertension; but more late adolescents with stage II hypertension. Likewise more middle adolescents were pre-diabetic, compared to their late counterparts. Therefore, there is need to address these disorders at early teen years for effective prevention. Furthermore, considering the gender distribution of participants with elevated BMI, more females were overweight and obese when compared to their male counterparts - such finding was reported in Sokoto state ${ }^{30}$.

This study reported the prevalence rate of prediabetes among the participants to be $9.4 \%$. This implies prediabetes is becoming common in our communities. Urgent steps are therefore needed to be taken to curtail its menace. Such steps include raising awareness of the disease and regular screening exercise among this population - as none of the participants had a previous knowledge of having the disease. This finding is in line with that of previous studies conducted in within and outside Nigeria ${ }^{13,16-18}$. It also affirms the report of global increasing trend of prediabetes prevalence, with majority unaware of their status ${ }^{13,31}$.

In addition, among the individual factors, age, religion and family history were statistically significant in developing prediabetes. That is, participants who are in middle adolescence, Muslim and had family history of DM are at more risk of developing prediabetes than their counterparts in late adolescence, Christian and had family history respectively. Meanwhile, findings from several studies have identified age as significant risk factor for development of pre-diabetes ${ }^{13,18,31,32}$. On family/ genetic history of DM, findings from several studies confirm the findings of this study. According to these studies, one of the risk factors for developing pre-diabetes and type II DM in children is having a parent/

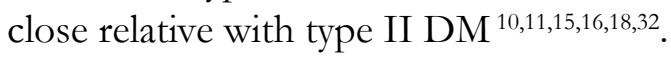

However, gender, type of school attended, physical activity, dietary habit and knowledge on diabetes mellitus were not statistically significant. As for gender, the finding was corroborated by that conducted in Cote d'Ivoire, which reported no significant difference in glycemic status of participants in terms of gender ${ }^{16}$. Finding from other studies was not in line with this study, as male gender was identified as significant risk factor for Impaired Fasting Glucose $e^{13,14,33}$. This variation may 
be as a result of socio-cultural difference from that of Africa, as these studies were conducted in Brazil and Arabian countries. For type of school attended, the finding of this study was not in line with that conducted in Ibadan, where attending private shool was reported as a factor increasing the odds for prediabetes ${ }^{17}$. Similarly on physical activity and dietary habit, the finding was not corroborated by others' findings; several studies reported risk factors for type II DM and prediabetes in children to include lack of physical activity or poor $\operatorname{diet}^{10,17,33,34}$. There is therefore need for further study to investigate this variation.

Further findings revealed that those with normal BMI are likely to develop prediabetes while obese/overweight adolescents are not, when compared to those that are underweight. This finding is not in line with many previous studies, which reported overweight/ obesity as a risk factor associated with developing prediabetes and $\mathrm{DM}^{10,13,15,17,33,35,36}$. However, this finding is in line with that conducted in Port-Harcourt, where no statistically significant difference in the prevalence of prediabetes between normal weight and overweight/ obese students was reported ${ }^{18}$. There is need for further study to compare the prevalence of pre-diabetes among underweight, normal, and overweight/obese adolescents, because almost all the previous studies compared between normal and overweight/obese adolescents. Hypertensive adolescents were also reported to likely develop prediabetes when compared to those with normal BP. This finding was corroborated by that of several studies, which reported hypertension as a risk factor for developing of prediabetes and $\mathrm{DM}^{10,15,17,18,31-33}$.

Among the interpersonal factors tested, only parents' dietary habit was statistically significant. That is, the healthier the dietary habit of the parents, the less likely their adolescents developing prediabetes. This finding is in line with that of previous studies37,38. They explained parents influence youth's eating behaviours through more unfavourable modelling of their parents, and by engaging in practices that affect availability of foods and beverages ${ }^{38}$. More so that parents are responsible for the food their children eat, the rules they follow, and the access they have to resources that promote and hinder positive health behavior ${ }^{37}$. Therefore parents need to be involved when counselling adolescents on their dietary habits for better results. The findings, that parents' physical activity habit was not statistically significant in their children developing prediabetes, was in line with report that even when parents take active role in the amount of physical activity their child participates in, it does not translate to reducing their risk of developing prediabetes ${ }^{37}$. Similarly, physical activity and dietary habit of friend were also not statistically significant in having prediabetes. This finding is not in consensus with the report that Type II DM occurs typically in adolescence, when peer influence predominates ${ }^{32}$. Findings also revealed adolescents whose parents were employed -traders, businessmen/women and public servants -were more likely to develop prediabetes compared to those with unemployed parents. This finding is in consensus with that of previous studies, which reported high family income as significant risk factor for DM and prediabetes ${ }^{11,13,31,37}$.

Lastly, among the community factors, only availability of healthy food in the school was statistically significant. That is, the more availability of food, fruits and vegetables and less availability of soft drink, snacks and biscuits in school, the less likelihood of the adolescents developing prediabetes. This implies schools are important stakeholder when considering healthy dietary habits in adolescents. This finding was in accordance with the report that schools play a critical role in improving the dietary behaviour of adolescents, by creating environments that are supportive of healthy eating and implementing policies and practices ${ }^{39}$. Other factors like availably of healthy food in the home, availability of sport facilities in school, school safety for sport, availability of healthy food in the neighbourhood, neighbourhood safety for exercise were not statistically significant in having pre-diabetes. This finding was not corroborated by previous studies. For instance, it has been documented that increased traffic and fast food locations, as well as decreased recreational space and safe sidewalks - resulting from environmental changes in communities - are affecting children's physical activity, sedentary, and nutrition behaviors ${ }^{40}$. It was also reported that children who were not attending a school considered to be safe had an increased likelihood of being overweight/obese ${ }^{37}$. This variation could be as a result of the study setting, which is a small, developing city, with little or no traffic and limited number of fast food locations.

\section{Conclusion}

Pre-diabetes is becoming a common problem among Nigerian adolescents, like their counterparts worldwide. There are many challenges associated with this; as this is an emerging health issue for this population. There is therefore need for stakeholders at all levels, to face this 
challenge before it becomes endemic problem in our country.

\section{Conflict of interest \\ None}

\section{References}

1. WHO Regional Office for Africa. Research shows higher risk of developing Non-communicable diseases in Africa [nternet]. WHO Regional Office for Africa. 2016 [cited 2020 Jun 8]. Available from: https://www. afro.who.int/news/research-shows-higher-risk-developing-non-communicable-diseases-africa

2. WHO. African Noncommunicable Diseases [nternet]. WHO. 2020 [cited 2020 Jun 8]. Available from: https://www.who.int/nmh/ncd-tools/who-regions-african/en/

3. Ogurtsova K, da Rocha Fernandes JD, Huang Y, Linnenkamp U, Guariguata L, Cho NH, et al. IDF Diabetes Atlas: Global estimates for the prevalence of diabetes for 2015 and 2040. Diabetes Res Clin Pract. 2017 Jun 1;128:40-50.

4. Oguejiofor O, Odenigbo C, Onwukwe C. Diabetes in Nigeria: Impact, Challenges, Future Directions. Endocrinol Metab Syndr. 2014;3(2).

5. Pinhas-Hamiel O, Zeitler P. Pre-diabetes in children and adolescents: What does it mean? [Internet]. Medscape . 2013 [cited 2018 Sep 19]. Available from: https://www.medscape.com/viewarticle/776457

6. Mayer-Davis EJ, Kahkoska AR, Jefferies C, Dabelea D, Balde N, Gong CX, et al. ISPAD Clinical Practice Consensus Guidelines 2018: Definition, epidemiology and classification of diabetes in children and adolescents [Internet]. 2018 [cited 2019 Mar 15]. Available from: https://cdn.ymaws.com/www.ispad.org/ resource/dynamic/forums/20180430_035307_30710. pdf

7. Canadian Diabetes Association. Living with pre-diabetes [Internet]. Canadian Diabetes Association. 2018 [cited 2018 Sep 25]. Available from: https://www.diabetes.ca/diabetes-and-you/living-with-prediabetes

8. Stefanaki C, Bacopoulou F, Peppa M. Prediabetes and adolescence-trends, causes, effects, and screening. Vol. 12, US Endocrinology. Touch Briefings; 2016. p. 94-8.

9. Spanakis EK, Golden SH. Race/ethnic difference in diabetes and diabetic complications. Curr Diab Rep [Internet]. 2013 Dec [cited 2020 Aug 20];13(6):814-23. Available from: /pmc/articles/PMC3830901/?report $=$ abstract

10. New York State Department of Health. Children with Diabetes: A Resource Guide for Families and Schools [Internet]. 2012 [cited 2018 Apr 28]. Available from: https://www.health.ny.gov/publications/0944. pdf

11. Al Amiri E, Abdullatif M, Abdulle A, Al Bitar N, Afandi EZ, Parish M, et al. The prevalence, risk factors, and screening measure for prediabetes and diabetes among Emirati overweight/obese children and adolescents. BMC Public Health [Internet]. 2015 Dec 24 [cited 2020 Jun 9];15(1):1298. Available from: http://bmcpublichealth.biomedcentral.com/articles/10.1186/ s12889-015-2649-6

12. Okwechime IO, Roberson S, Odoi A. Prevalence and Predictors of Pre-Diabetes and Diabetes among Adults 18 Years or Older in Florida: A Multinomial Logistic Modeling Approach. Ciccozzi M, editor. PLoS One [Internet]. 2015 Dec 29 [cited 2020 Jun 9];10(12):e0145781. Available from: https://dx.plos. org/10.1371/journal.pone.0145781

13. Al-Rubeaan K. National surveillance for type 1, type 2 diabetes and prediabetes among children and adolescents: A population-based study (SAUDI-DM). J Epidemiol Community Health. 2015 Jun 17;69(11):1045-51.

14. Chahkandi T, Taheri F, Bijari B, Kazemi T, Namakin $\mathrm{K}$, Zardast M. Prevalence of high normal FBS and prediabetes among adolescents in Birjand, East of Iran, 2012. J Educ Health Promot [nternet]. 2015 [cited 2020 Jun 9];4(1):68. Available from: http://www.jehp.net/ text.asp?2015/4/1/68/162389

15. Lukács A, Kiss-Tóth E, Csordás Á, Sasvári P, Barkai L. Screening risk factors for type 2 diabetes in overweight and obese adolescents in school settings of Hungary: A population-based study. J King Sand Univ Sci. 2018 Apr 1;30(2):176-9.

16. Agbre-Yace ML, Oyenusi EE, Oduwole AO, Ake MD, Abodo JR. Prevalence of diabetes mellitus among children and adolescents in the district of Abidjan in Cote d'Ivoire: A population-based study. J Diabetes Metab Disord. 2016 Sep 20;15(1):1-9.

17. Arigbede O, Adeoye I, Jarrett O, Yusuf O. Prediabetes among Nigerian adolescents: A School-based study of the prevalence, risk factors and pattern of fasting blood glucose in Ibadan, Nigeria. Int J Diabetes Dev Ctries. 2017 Dec 1;37(4):437-45.

18. Jaja T, Oduwole AO, Fetuga B, Abdus-Salam IA. Prevalence of prediabetes in secondary school students in Port Harcourt, Nigeria. African J Diabetes Med. 2015;23(1).

19. Center for Disease Control and Prevention. The social-ecological model: A framework for prevention for individual and social violence. [Internet]. CDC Di- 
vision of Cancer Prevention and Control. 2015 [cited 2018 Jun 26]. Available from: https://www.cdc.gov/ cancer/crccp/sem.htm $2 / 2$

20. Poux S. Social Ecological Model Offers New Approach to Public Health [Internet]. The Borgen Project. 2017 [cited 2020 Jun 26]. Available from: https://borgenproject.org/social-ecological-model/

21. U.S. Department of Health and Human Services, U.S. Department of Agriculture. Everyone Has a Role in Supporting Healthy Eating Patterns: The Social-Ecological Model-2015-2020. In: 2015-2020 Dietary Guidelines for Americans [Internet]. $8^{\text {th }}$ ed. 2015 [cited 2020 Jun 9]. p. 64-6. Available from: http://health. gov/dietaryguidelines/2015/guidelines/

22. Israel GD. Determining Sample Size [Internet]. 2003 [cited 2020 Jun 10]. Report No.: PEOD6. Available from: http://www.gjimt.ac.in/web/wp-content/ uploads/2017/10/2_Glenn-D.-Israel_Determining-Sample-Size.pdf

23. National Bureau of Statistics. Annual abstract of statistics. Abuja; 2010.

24. World Health Organisation. Adolescent health [Internet]. World Health Organisation. 2020 [cited 2020 Aug 20]. Available from: https://www.who.int/ health-topics/adolescent-health\#tab=tab_1

25. McLarty C. Development of a questionnaire to assess knowledge in women with gestational diabetes [Internet]. Department of Nursing. Edith Cowan University; 1993 [cited 2018 Aug 30]. Available from: https:/ / ro.ecu.edu.au/theses_hons/639

26. Godin G, Shephard RJ. Leisure-Time Exercise Questionnaire. Med Sci Sport Exerc [Internet]. 1997 [cited 2018 Sep 19];June(S36 - S38). Available from: http://www.godin.fsi.ulaval.ca/Fichiers/Quest/Godin leisure-time.pdf

27. Johnson F, Wardle J, Griffith J. The adolescent food habits checklist: Reliability and validity of a measure of healthy eating behaviour in adolescents. Eur J Clin Nutr. 2002 Jun 25;56(7):644-9.

28. Flynn JT. 2017 AAP Guidelines for Childhood Hypertension. Am Acad Pediatr [Internet]. 2017;140(3): 1-74. Available from: https://solutions.aap.org/DocumentLibrary/pcowebinars/2017 Hypertension Webinar.pdf

29. Johns Hopkins Medicine. Preventing Obesity in Children, Teens, and Adults [Internet]. Johns Hopkins Medicine. 2019 [cited 2019 Sep 30]. Available from: https://www.hopkinsmedicine.org/health/conditions-and-diseases/obesity/preventing-obesity

30. Ahmad M, Ahmed H, Airede K. Body mass index among school adolescents in Sokoto, North-Western Nigeria. Sabel Med J. 2013;16(1):5.

31. Akter S, Mizanur Rahman M, Abe SK, Sultana P. Prevalence of Diabetes and Prediabetes and Their Risk Factors Among Bangladeshi Adults: A Nationwide Survey. Bull World Health Organ. 2014 Mar;92(3).

32. Zeitler P, Arslanian S, Fu J, Pinhas-Hamiel O, Reinehr T, Tandon N, et al. Type 2 Diabetes (T2D) in Youth [Internet]. 2018 [cited 2020 Jun 10]. Available from: https://www.ispad.org/resource/dynamic/forums/20180111_100828_25267.pdf

33. Lima ACS, Araújo MFM, Freitas RWJF de, Zanetti ML, Almeida PC de, Damasceno MMC. Risk factors for Type 2 Diabetes Mellitus in college students: association with socio-demographic variables. Rev Lat Am Enfermagem. 2014;22(3):484-90.

34. Arti D, Shah AD, Vittinghoff E, Kandula NR, Srivastava S, Kanaya AM. Correlates of prediabetes and type II diabetes in US South Asians: Findings from the Mediators of Atherosclerosis in South Asians Living in America (MASALA) study. Ann Epidemiol. 2015 Feb 1;25(2):77-83.

35. Haemer MA, Grow HM, Fernandez C, Lukasiewicz GJ, Rhodes ET, Shaffer LA, et al. Addressing prediabetes in childhood obesity treatment programs: Support from research and current practice. Child Obes. 2014;10(4):292-303.

36. Ranjani H, Pradeepa R, Mehreen T, Anjana R, Anand $\mathrm{K}$, Garg R, et al. Determinants, consequences and prevention of childhood overweight and obesity: An Indian context. Indian J Endocrinol Metab. 2014;18(Suppl 1):S17-25.

37. Callahan K. Assessing the Social and Ecological Factors that Influence Childhood Overweight and Obesity [Internet]. East Tennessee State University; 2014 [cited 2020 Jun 10]. Available from: https://dc.etsu.edu/etd/2454

38. Reicks M, Banna J, Cluskey M, Gunther C, Hongu $\mathrm{N}$, Richards R, et al. Influence of parenting practices on eating behaviors of early adolescents during independent eating occasions: Implications for obesity prevention. Nutrients. 2015;7(10):8783-801.

39. Center for Disease Control and Prevention. School Health Guidelines [Internet]. CDC. 2017 [cited 2018 Aug 31]. Available from: https://www.cdc.gov/healthyschools/npao/strategies.htm

40. Giles-Corti B, Kelty SF, Zubrick SR, Villanueva KP. Encouraging walking for transport and physical activity in children and adolescents: How important is the built environment? Sport Med. 2009;39(12):995-1009. 